DOI: 10.1590/permusi2015a3106

\title{
Flautas Transversais Renascentistas: história, construção e experimento com madeiras brasileiras
}

\author{
Rodrigo Bueno Ferreira (UFPR, Curitiba, PR) \\ ruod_rik@ymail.com
}

Henry Maas (UFPR, Curitiba, PR)

krisium@gmail.com

Luiz Cesar Savi (UFPR, Curitiba, PR)

savi@sul.com.br

Thiago Corrêa de Freitas (UFPR, Curitiba, PR)

tcf@ufpr.br

\begin{abstract}
Aloísio Leoni Schmid (UFPR, Curitiba, PR) iso@ufpr.br
\end{abstract}

\begin{abstract}
Resumo: Originária da flauta transversal alemã do séc. XII, a flauta transversal renascentista, também chamada de traverso, atingiu o ápice de sua popularidade entre os séculos XVI e XVII. Como tantos outros instrumentos musicais acústicos, as técnicas para sua construção e para seleção dos materiais utilizados, em especial das madeiras, são ditadas muito mais pela tradição e por generalizações intuitivas do que por indicações resultantes de pesquisa científica empírica. Este trabalho descreve uma breve história das flautas renascentistas, sua utilização, suas formas de execução e, principalmente, sua construção, a fim de avaliar até que ponto a seleção de materiais é importante para determinar as características qualitativas do instrumento, sendo que para este último ponto, foram utilizadas madeiras nacionais não tradicionais (como imbuia e sucupira), para a confecção, gerando bons exemplares.
\end{abstract}

Palavras Chave: flauta transversal renascentista; música da renascença; construção de instrumentos musicais; madeiras brasileiras na luteria.

\section{Renaissance transverse flute: history, construction and experiment with Brazilian woods}

\begin{abstract}
Originated from the German Querflöte from the 12th century, the Renaissance transverse flute reached its highest popularity between the 16th and 17th centuries. Like several other acoustical musical instruments, the Renaissance transverse flute has its material selection, as well as its construction technique dictated by tradition and intuitive generalization rather than by scientific empirical research. This paper presents a brief history of Renaissance flutes and their making. We also have evaluated, in a qualitative way, the relevance of material selection for the instrument features. So far, it was possible to show the feasibility of a nontraditional wood choice, as Brazilian woods (such as imbuia and sucupira) were chosen to build and yielded good exemplars of this instrument. Keywords: Renaissance transverse flute; Renaissance music; Musical instruments making; Brazilian woods in instrument making.
\end{abstract}

\section{1 - Introdução}

Entre os construtores de instrumentos musicais, há consenso de que a seleção dos materiais é fundamental para se obter um instrumento de qualidade. Por seus atributos sonoros e estéticos, a nobreza de algumas madeiras, tais como o jacarandá, o ébano e o pau-brasil, goza de amplo apreço entre os 
especialistas. Observamos, porém, que algumas hipóteses qualitativas atribuídas a alguns instrumentos são generalizações de resultados obtidos a partir de outros. Por exemplo, os instrumentos da família do violino, os violões e os demais instrumentos com caixa de ressonância recebem considerável influência da escolha da madeira para seu desempenho sonoro. A partir da eficiência acústica da madeira para a produção de um instrumento com caixa de ressonância, é comum sua generalização para qualquer outro tipo de instrumento, como os elétricos e os de sopro.

Tomando o exemplo da guitarra elétrica, alguns estudos, como o de PEREIRA, LAIBIDA JUNIOR e FREITAS (2010) e os de FLEISCHER e ZWICKER (1998 e 1999), demonstraram que a influência da madeira selecionada para a confecção do corpo do instrumento parece ser quase nula na qualidade sonora do instrumento. BENFATTI e colaboradores (2012, p.5) sugerem que, ao invés de necessariamente acústicas, a explicação sobre a apreciação de determinadas madeiras pode ser de outra ordem, como tradição, estética, cultura, durabilidade e disponibilidade.

Desta forma, algumas afirmações sobre a construção de instrumentos musicais acabam situadas em um âmbito dedutivo. O conhecimento intuitivo é elementar para qualquer um que se dedique à construção de instrumentos, considerando que é uma arte. Porém, ao mesmo tempo em que a intuição facilita a criatividade artística, pode também conduzir a generalizações precipitadas. Por este motivo, nos propusemos a investigar se as flautas são afetadas pela escolha do material do mesmo modo que os instrumentos com caixa de ressonância.

Neste trabalho introdutório, nos esforçamos para a descrição de um estudo empírico, que possa servir de referência àqueles que se interessam pela construção de flautas. Em nosso procedimento, utilizamos o mesmo projeto, os mesmos equipamentos e técnicas para a construção de cinco instrumentos, com diferentes madeiras. Tais flautas foram posteriormente analisadas e comparadas, com o propósito de definir diferenças qualitativas nos processos de produção e também na qualidade final dos instrumentos.

O artigo está organizado de maneira que, primeiramente é explanada a utilização musical da flauta renascentista, suas características e outras pesquisas sobre instrumentos de época; em seguida, são descritos os procedimentos de construção; logo após, apresentada a análise comparativa entre os exemplares de diferentes madeiras; e, finalmente, nossas considerações.

\section{2 - Panorama Histórico}

A flauta transversal renascentista teve o seu ápice no período que vai da segunda metade do século XVI até a primeira metade do XVII, praticamente sem sofrer alterações nesse tempo. Segundo o construtor contemporâneo PUGLISI $^{1}$ (1995, p.7), isso reflete o compromisso ideal entre as necessidades musicais daquela época e as limitações do corpo, como o tamanho dos dedos e 0 alcance das notas. Somente 43 instrumentos originais daquele período 
sobreviveram até os dias atuais. Destes, 26 se encontram na Itália, reunidos em grupos, rever todo o artigo de PUGLISI (1979), fato condizente com a prática deste instrumento na Renascença, período em qual não se criava instrumento para ser utilizado por solistas, mas sim conjuntos de instrumentos que formavam um consorte (BYRNE, 1965, p.126).

A história do traverso remonta a região da atual Alemanha, no séc. XII, onde após ter sido admitido como instrumento musical nos círculos aristocráticos, passa também a ser tocado em conjunto com a rabeca dos Minnesinger? Segundo BROWN (1980), rever todo o conteúdo do artigo para uma melhor contextualização, e SMITH (1992, p.13) sua popularização o faz chegar até a França no séc. XIV e ao norte da Itália no séc. XV, e já em meados do séc. $\mathrm{XVI}$, o traverso evoluiu para um pífano de uso militar na Alemanha e na Itália, sendo que na França consolidou-se com instrumento de música de câmara (CAZEAUX, 1975, p.54-57).

Por ser um instrumento constituído de peça única, não é possível afinar a flauta com outro instrumento de referência, e a solução encontrada na época para contornar o problema foi construir várias delas em diferentes tamanhos e afinações. Este fato deve ter colaborado para a existência de um grande número de flautas, de diferentes tamanhos, listados em inventários, como o feito em 1589 em Stuttgart, em que estão registrados 220 exemplares do instrumento (Castellani, citado por ALLAIN-DUPRE, 2000, p.52). Além disso, o traverso era considerado um belo instrumento musical e também um objeto de colecionador. Isto pode ser verificado através do caso da Accademia Filarmonica de Verona, que em 1569 contava com dois conjuntos de cinco flautas cada e ainda alguns instrumentos avulsos; já no ano de 1628, um inventário aponta a existência de 51 flautas. A Accademia ${ }^{3}$ perdura até os dias atuais e mantém o maior conjunto de flautas renascentistas (PUGLISI, 1995, p.37), rever também todo o artigo do mesmo autor que trata exclusivamente destas flautas (PUGLISI, 1979).

Atualmente existem três principais tratados que remontam ao período áureo das flautas transversais renascentistas, sendo considerados as fontes primárias de informações, não apenas sobre o traverso, mas de vários instrumentos, como demonstra a sua utilização no trabalho de CEULEMANS (2011, cap.3) sobre as origens do violino. São eles em ordem cronológica Musica getutscht, de Sebastian VIRDUNG (1511), Musica instrumentalis deudsch, de Martin AGRICOLA (1529 e 1545) e Harmonie Universelle, de Marin MERSENNE (1636). Existem também algumas informações sobre o instrumento no manual de música e dança da Renascença Orchesographie, de Thoinot ARBEAU (1589), no tratado De musica, de Jerôme CARDAN (1546), em II dolcimelo, de Aurelio VIRGILIANO (1590), na Pratica di Musica, de Lodovico ZACCONI (1592), também em Selva de varii passaggi, de Francesco ROGNONI (1620), no Traité des instruments de musique, de Pierre TRICHET (1640) e em Der Fluyten-Lust-hof, de Jacob van EYCK (1649). A obra de referência musical mais antiga destinada às flautas a que se tem acesso atualmente consiste nas Vingt et sept chansons musicales à quatre, de Pierre ATTAINGNANT (1533). Nesta coleção, cada canção (chanson) é designada 
para ser tocada com flauta transversal da renascença, com flauta doce ou por ambos. Como as vozes intermediárias partilham da mesma extensão musical, se presume que o conjunto de flautas era constituído por uma flauta mais aguda, duas de tessitura intermediária e uma flauta baixo (SACHS 1940, p.314). Naquele período da história, não havia uma convenção internacional para a padronização da frequência utilizada na afinação, variando de cidade para cidade e até mesmo de igreja para igreja de uma mesma cidade. HELMHOLTZ (1954, p.493-513) construiu uma história das referências de afinação na Europa desde o séc. XIV até meados de 1880. Seu trabalho demonstrou diferenças substanciais nas frequências de afinação. Michael Praetorius (Praetorius, citado por SMITH,1992, p.16), relatou que várias regiões de influência católica possuíam duas referências para a afinação: o tom de câmara (kammerton), utilizada para a música profana; e o tom de coro (chorton), utilizado para música sacra, sendo esta mais grave que a anterior e a que geralmente se utilizava para a afinação dos traversos.

Os trabalhos de PUGLISI (1979, 1988 e 1995) e ALLAIN-DUPRE (2000, 2004 e 2006), apresentaram medidas e desenhos de instrumentos do século XVI em bom estado de conservação. Várias características comuns foram observadas: na maioria das flautas a embocadura é elipsoidal e não circular, sendo que a elipse possui o raio maior na direção do comprimento do instrumento; o furo transversal é praticamente cilíndrico, apenas com algumas imperfeições, que a princípio devem-se mais ao sistema de furação utilizado na época (BAINES, 1957, p.277) do que a um projeto consciente ${ }^{4}$; os furos laterais das flautas estão agrupados, por proximidade, em dois grupos de três furos cada; em certas flautas, a distância entre a embocadura e o final fechado do tubo é igual à distância entre o primeiro furo e o final aberto do tubo; a razão entre o comprimento vibrante (distância do final mais afastado da embocadura até 0 centro da embocadura) pelo diâmetro do furo transversal varia entre 30 até 33, sendo apenas um pouco menor que estes valores para as flautas baixo; devido às finas paredes e ao tipo de madeira utilizada, as flautas renascentistas são muito leves, tendo entre 90 e 170 gramas. Segundo BRAGARD (1968, p.101) a flauta tenor feita por Claude Rafi (1515 -1553), para uma breve biografia rever todo o artigo de TRICOU (1903), exposta no Museu de Instrumentos Musicais de Bruxelas, é feita com madeira de buxinho (Buxus sempervirens).

Não encontramos muitos indícios de outras madeiras utilizadas no conjunto destas flautas além do buxinho. A literatura, contudo, aponta algumas tendências: SCHWANKL (1955, p.94 e 106) menciona serem a bétula e a pereira adequadas à fabricação de instrumentos de sopro, e o pinus na fabricação de órgãos de tubo; ROBINSON (1980, p.10) menciona o buxinho como a madeira mais dura e com mais fina grã disponível na Europa, portanto utilizada na confecção de flautas. Esta madeira, porém, apresenta pronunciada tendência a empenar, motivo pelo qual se encontram muitas flautas antigas arcadas. O buxinho é difícil de ser obtido em peças maiores e sua cor é indefinida, sendo comumente colorido através de produtos químicos, como o ácido nítrico, para se chegar à rica cor amarelo-alaranjada. Como alternativa, ROBINSON (1980, p.11) alude à madeira de árvores frutíferas, recomendando o hard maple (Acer saccharum) e frutíferas da América do Norte: macieira, 
cerejeira e pereira. Menciona que durante o século XIX, madeiras tropicais gradualmente substituíram as madeiras do hemisfério Norte.

Segundo RICHTER (1988, p.19-20), ao lado da pereira (Pirus communis), o maple (Acer pseudoplatanus) é a madeira mais utilizada na fabricação de flautas doces. Ambas são classificadas como madeiras leves neste âmbito. Seu timbre é, correspondentemente, tido como macio e centrado no tom fundamental. O buxinho foi utilizado sucessivamente no passado, mas, devido à baixa produção, é utilizado somente em réplicas de flautas históricas. Já o jacarandá da Bahia (Dalbergia nigra) é conhecido e apreciado na Europa há mais de 200 anos - mas provavelmente, não remonta à Renascença. O ébano, por sua vez, teve grande tradição na confecção de instrumentos de sopro de alto valor (no entanto, cabe possível observação quanto à adequação, em especial, a instrumentos chaveados, em que a fixação de pequenos parafusos tem no ébano uma madeira privilegiada).

RICHTER (1950, p.23 e 31) afirma que o pau rosa (Dalbergia decipularis) e a oliveira (Oleaeuropea, usada em instrumentos de alto valor, com fácil produção de som e tom quente e cheio) são madeiras conhecidas há séculos e adequadas à fabricação de flautas mais agudas. Ao comentar as características especiais para madeiras não ressonantes, o caso das flautas, o autor menciona o acabamento superficial obtido e, nesta característica, destaca o grenadillo ou pau preto (Dalbergia melanoxylon), com uma lisura "cega", a madeira mais pesada, mais dura e mais seca (granulosa), que produz timbre claro e brilhante, elegante e rico em harmônicos, portanto adequado ao solo. Por fim, menciona a ameixeira (Prunus domestica). Algumas propriedades das madeiras tradicionais são apresentadas no Ex.1.

\begin{tabular}{|l|l|l|}
\hline $\begin{array}{l}\text { Nome } \\
\text { comum }\end{array}$ & $\begin{array}{l}\text { Nome } \\
\text { científico }\end{array}$ & Propriedades \\
\hline Pereira & Pirus communis & $\begin{array}{l}\text { Densidade entre 0,65 e 0,76 g/cm³ variações } \\
\text { dimensionais médias a fortes; bastante dura, } \\
\text { dificilmente rachada, facilmente curvada, } \\
\text { especialmente apropriada para o torneamento, } \\
\text { entalhe, decapagem e polimento; resistente a } \\
\text { fungos e intempéries; forte tendência a rachar na } \\
\text { secagem. }\end{array}$ \\
\hline Maple & $\begin{array}{l}\text { Acer } \\
\text { pseudoplatanus }\end{array}$ & $\begin{array}{l}\text { Densidade entre 0,5 e 0,75 g/cm³; variações } \\
\text { dimensionais médias; dura, elástica e tenaz, com } \\
\text { alta resistência à abrasão; boa trabalhabilidade } \\
\text { em especial perfilagem, torneamento, entalhe, } \\
\text { decapagem e polimento. Dificilmente rachada, } \\
\text { facilmente curvada, permeável, suscetível a } \\
\text { ataque de fungos, sem resistência às intempéries. } \\
\text { Racha facilmente na secagem. }\end{array}$ \\
\hline
\end{tabular}




\begin{tabular}{|l|l|l|}
\hline Buxinho & $\begin{array}{l}\text { Buxus } \\
\text { sempervirens }\end{array}$ & $\begin{array}{l}\text { Densidade entre } 0,85 \text { e } 1,02 \mathrm{~g} / \mathrm{cm}^{3}, \text { fortes } \\
\text { variações dimensionais, tende a rachar na } \\
\text { secagem e se deformar bastante, muito dura e } \\
\text { densa, superfícies aplainadas muito endurecidas } \\
\text { e lisas, muito trabalháveis em especial em } \\
\text { torneamento, furação, perfilação, decapagem e } \\
\text { polimento. Muito sensível à umidade e ataque de } \\
\text { fungos, não resistente às intempéries. }\end{array}$ \\
\hline
\end{tabular}

Ex.1 - Tabela das propriedades das madeiras tradicionalmente utilizadas na fabricação de flautas.

\section{3 - Da história à construção: procedimentos práticos}

Os procedimentos de construção que adotamos podem ser sumarizados em: 1) Escolha das madeiras; 2) Preparação; 3) Torneamento externo; 4) Furação longitudinal; 5) Torneamento segunda etapa; acabamento externo5; 6) Préacabamento (lixamento no torno); limpeza das rebarbas e arestas; 7) Furação da embocadura e dos furos laterais; 8) Afinação; 9) Acabamento (lixamento e revestimento com óleo e cera).

Para a construção das flautas, foi utilizado um manuscrito da planta de PUGLISI ${ }^{6}$, com as dimensões, posições e diâmetros dos furos laterais, instrumento baseado no de VAN EYCK (1649), porém com afinação atual $($ Lá $=440 \mathrm{~Hz})$. Foram escolhidas cinco diferentes madeiras com diferentes características (Ex.2 de A até E), sendo elas a araucária, o cedro, a imbuia, a sucupira e o roxinho. Constam também os nomes científicos das respectivas madeiras, obtidos de LORENZI (2008 e 2009). Os principais equipamentos utilizados consistem em um torno mecânico IMOR PRN-320 - que, para as dimensões do projeto escolhido, deve ter distância entre pontas superior a 500 $\mathrm{mm}$, e diâmetro do furo do eixo do cabeçote fixo superior a $27 \mathrm{~mm}$ - com luneta fixa e uma furadeira de bancada. Também foi utilizada uma broca longa de diâmetro $15 \mathrm{~mm}$ e comprimento $450 \mathrm{~mm}$, além das brocas comuns, com os diâmetros de $5,4 \mathrm{~mm}, 5,5 \mathrm{~mm}, 5,8 \mathrm{~mm}, 6,0 \mathrm{~mm}$ e $7,5 \mathrm{~mm}$.

\begin{tabular}{|l|l|l|l|}
\hline Designação & Nome comum & Nome científico & Massa (g) \\
\hline A & Araucária & Araucariaangustifolia & 70,4 \\
\hline B & Cedro & Cedrelafissilis & 65,2 \\
\hline C & Imbuia & Ocotea porosa & 91,2 \\
\hline D & Sucupira & Pterogynenitens & 112,7 \\
\hline E & Roxinho & Peltogyne confertiflora & 121,5 \\
\hline
\end{tabular}

Ex.2 - Tabela da designação dos instrumentos construídos, de A a E, o nome vulgar da madeira utilizada na sua construção, o nome científico desta madeira e a massa do instrumento, a qual foi medida a temperatura de $24^{\circ} \mathrm{C}$ e $53 \%$ de umidade relativa do ar.

Escolhidas as madeiras ${ }^{7}$, o primeiro passo para a construção foi o corte de um paralelepípedo, com dimensões aproximadas de $520 \mathrm{~mm}$ por $40 \mathrm{~mm}$ por 40 $\mathrm{mm}$ para cada madeira. Para simplificar o torneamento, foi funcional retirar com uma plaina o excesso de madeira em cada aresta no sentido do comprimento, de maneira a dar à peça uma seção octogonal (não 
necessariamente regular). Cada uma dessas peças de madeira foi fixada adequadamente no torno para serem transformadas em cilindros com dimensões aproximadas de $500 \mathrm{~mm}$ de comprimento por $27 \mathrm{~mm}$ de diâmetro, (Ex.3 foto (1)). Uma vez produzidos os cilindros, seguiu-se a realização do furo transversal, feito a partir da fixação de uma broca longa (comprimento útil superior à metade do comprimento da flauta) no mandril do cabeçote móvel do torno. O cilindro de madeira foi fixado na placa do torno e sua outra extremidade alinhada com a ponta cortante da broca, através de uma luneta fixa (ver a montagem no Ex.3 fotos (2) e (3)). Nesta montagem a broca permanece estacionária e o cilindro passa a rotacionar apoiado na luneta fixa.

Desta forma, procedeu-se à perfuração até ser atingido o meio geométrico do cilindro, realizando-se, então, uma inversão do cilindro de madeira, para passar a perfurar a partir da outra extremidade, até 0 encontro com 0 furo anteriormente iniciado.
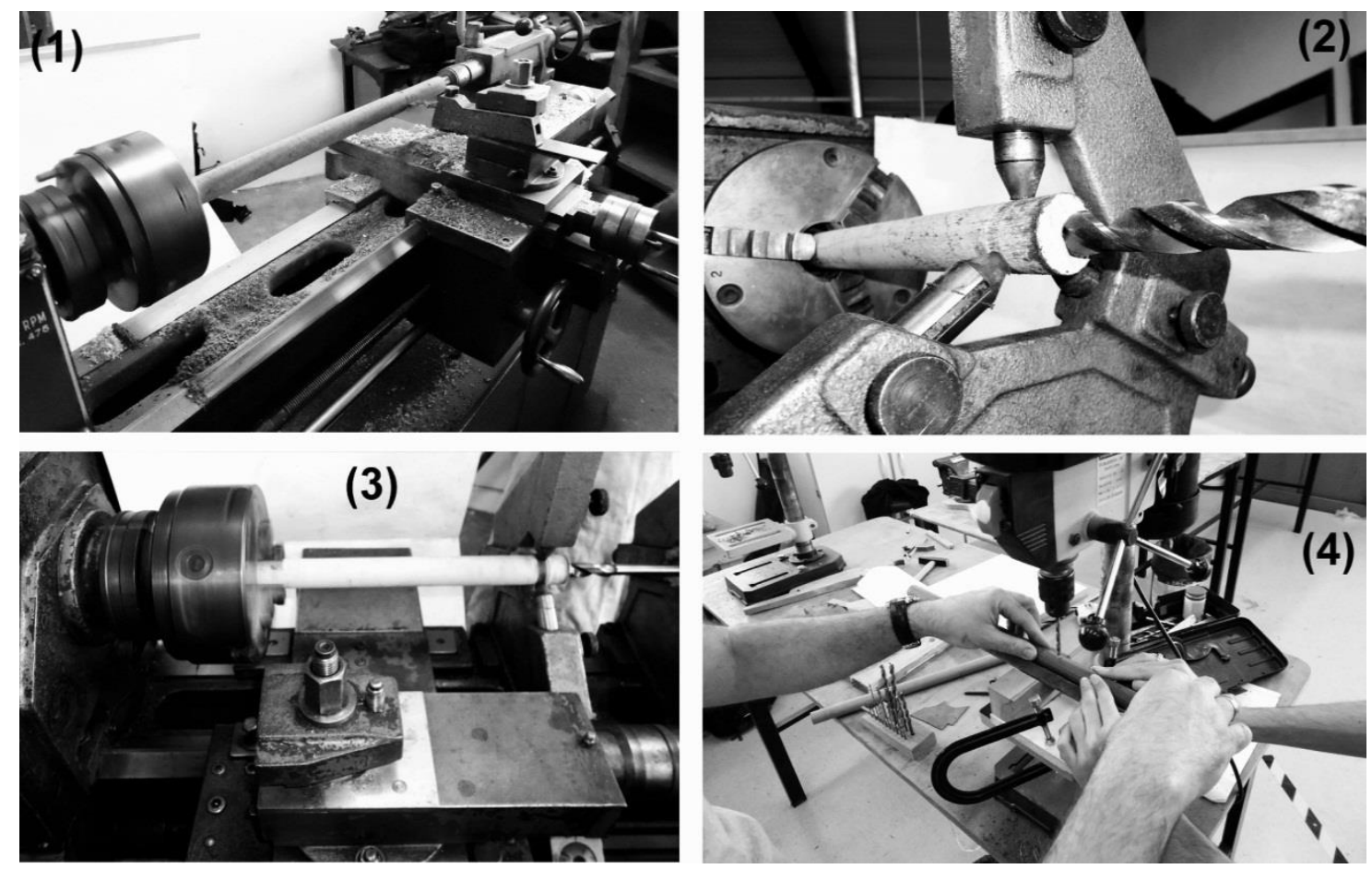

Ex.3 - Ilustração de alguns procedimentos do processo de construção da flauta renascentista: (1) torneamento do cilindro; (2) alinhamento da broca com o cilindro de madeira, utilização da luneta fixa; (3) furação transversal do cilindro; (4) furação lateral do cilindro.

Uma vez feito o furo transversal, o cilindro foi novamente colocado no torno para ter o seu diâmetro reduzido de $27 \mathrm{~mm}$ para $23 \mathrm{~mm}$, deixando $1 \mathrm{~mm}$ de margem, para que fosse feito o acabamento nos diâmetros externos do tubo (Ex.4). Nesta etapa é recomendável o torneamento entre pontas (com uso de placa de arrasto), para garantir a concentricidade entre o furo longitudinal e a superfície externa da flauta (uniformidade da parede do instrumento). Em seguida, o cilindro foi lixado, com lixa de gramatura 80 , seguida de gramatura 120 , tanto externamente como internamente. Após serem feitas as marcações das posições da embocadura e dos seis furos laterais, respeitando os valores do projeto, os furos laterais foram feitos com as brocas nos devidos diâmetros, 
utilizando a furadeira de bancada (ver Ex.3 foto (4)). Também é recomendável o uso de um apoio em forma de prisma negativo, para que o cilindro não escorregue, mas possa ser movido no sentido do comprimento e também possa ser rotacionado.

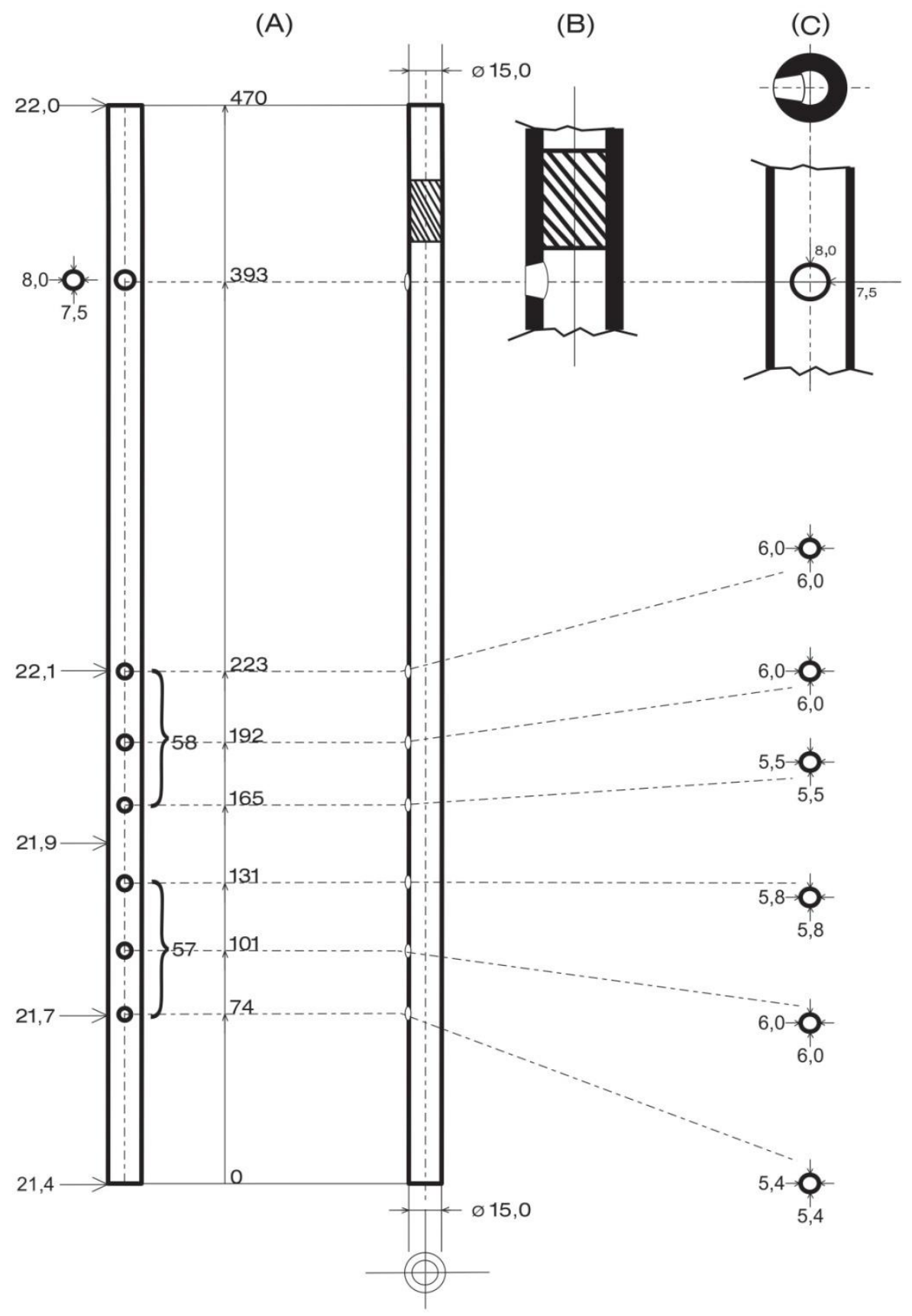

Ex.4 - Representação técnica do instrumento, medidas em milímetros. A seção (A) mostra a flauta de frente e de lado, os números à esquerda são do diâmetro do tubo ao longo do comprimento. As seções (B) e (C) apresentam detalhes da região da embocadura.

Devido aos processos anteriores, os cilindros apresentam rebarbas externas e internas, tendo sido removidas com lixas de gramatura 120, 180, 220 e 240. Por fim, utilizou-se lã de aço para obter um acabamento mais refinado. Os furos laterais também foram trabalhados, com lixa de gramatura 280, para que não sofressem um aumento indesejado no seu diâmetro. Em seguida, foram 
realizados alguns pré-ajustes no ângulo em que o furo lateral encontra o furo transversal, passando este a ser menor que $90^{\circ}$. Também foi realizado um préajuste mais complexo na embocadura, seguindo as indicações existentes nos projetos de PUGLISI (1995). A fim de ser obtida a impermeabilização parcial da parte interna do tubo, utilizou-se óleo de linhaça.

Foi confeccionada a rolha - peça cilíndrica em cortiça de cerca de $30 \mathrm{~mm}$ de comprimento com o mesmo diâmetro do tubo, para fechar a extremidade mais próxima à embocadura - e ajustada no interior do tubo, para reprimir a passagem de ar. $O$ posicionamento da rolha tem forte influência na qualidade sonora do instrumento, ficando geralmente afastada da embocadura a uma distância igual ao diâmetro do tubo. Após a colocação da rolha, realizou-se o ajuste da embocadura, de forma que o instrumento produzisse som claro, com relativa facilidade de execução (é recomendável reposicionar a rolha após este ajuste, visando melhorar ainda mais a qualidade sonora).

Passou-se, então, ao processo de afinação das notas correspondentes aos furos laterais. Para tanto, foram feitos pequenos desgastes para alterar 0 ângulo de encontro entre o furo lateral e o furo transversal. A cada pequeno ajuste, a frequência da nota foi conferida com um afinador digital cromático (Korg modelo Tm 40), procedendo-se do grave para o agudo, conforme a tabela de digitação no Ex.5. Existem outras possibilidades de digitações (ALLAIN-DUPRE, 2000, p.34 e 38). 

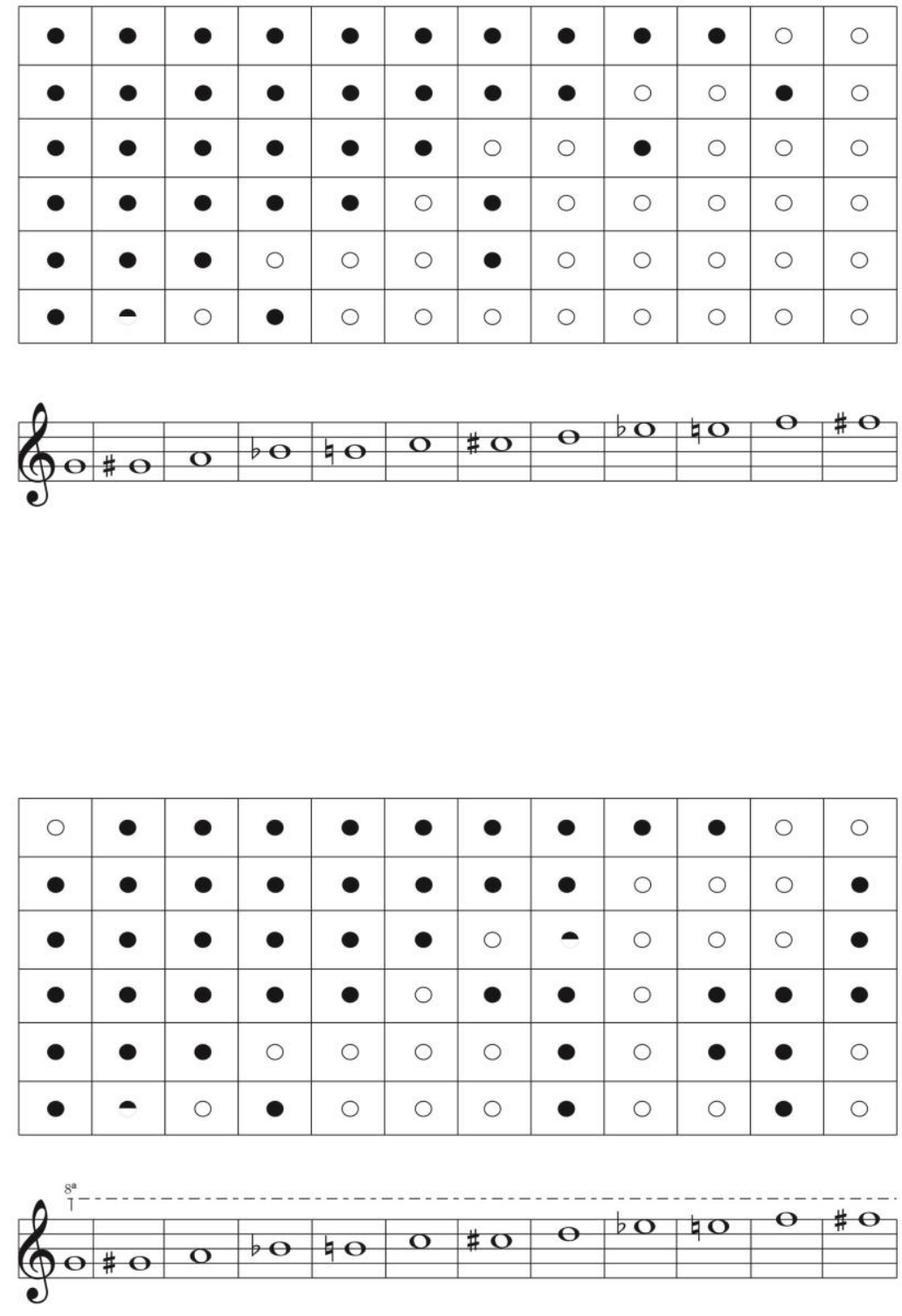

Ex.5 - Tabela de digitação das notas. Círculos preenchidos são furos fechados e círculos não preenchidos são furos abertos. Círculos parcialmente preenchidos são furos parcialmente fechados. A parte superior corresponde ao furo mais próximo da embocadura.

Uma vez completo o processo de afinação, foi novamente aplicado óleo de linhaça na parte interna. Já para o acabamento externo, aplicou-se cera de abelhas, passada a frio. É válido notar que o bloco de cera deve ser friccionado contra a flauta até besuntá-la. Em seguida, com o uso do soprador térmico, a cera foi derretida até formar uma camada homogênea sobre a superfície 
externa da flauta. Para dar brilho e retirar o excesso de cera foi realizado o processo de polimento.

\section{4 - Análise comparativa entre os instrumentos}

Antes de fazer a análise, convém observar algumas características das madeiras utilizadas para a construção dos instrumentos. Para tanto, utilizamos as informações levantadas por LORENZI (2008 e 2009), as quais devem justificar os resultados aqui obtidos:

A araucária $(\mathbf{A})$ ocorre desde Minas Gerais e Rio de Janeiro, em altitudes acima de $900 \mathrm{~m}$, até a região Sul, acima de $500 \mathrm{~m}$. A sua madeira possui densidade $0,55 \mathrm{~g} / \mathrm{cm}^{3}$, sendo considerada uma madeira leve, macia e pouco durável (LORENZI, 2008, p.17). WEHRe TOMAZELLO FILHO (2000, p.163) comentam que a densidade média da madeira de araucária, procedente de árvores mais velhas, pode variar entre 0,6 e $0,7 \mathrm{~g} / \mathrm{cm}^{3}$.

O cedro (B) ocorre desde o Rio Grande do Sul até Minas Gerais. A madeira possui densidade $0,55 \mathrm{~g} / \mathrm{cm}^{3}$, o que a faz ser considerada de leve a moderadamente pesada, macia, sendo bastante durável em ambiente seco, porém quando enterrada ou submersa apodrece rapidamente (LORENZI, 2008, p.266).

A imbuia (C) ocorre no Paraná, Santa Catarina e Rio Grande do Sul. Sua madeira é moderadamente pesada, densidade $0,65 \mathrm{~g} / \mathrm{cm}^{3}$, dura, de cor muito variada, superfície irregularmente lustrosa e lisa, medianamente resistente e de grande durabilidade mesmo quando exposta ao tempo (LORENZI, 2008, p.221).

A sucupira (D) ocorre no nordeste do Brasil até o oeste de Santa Catarina. Sua madeira é moderadamente pesada, densidade $0,77 \mathrm{~g} / \mathrm{cm}^{3}$, dura, textura média, grã direta e irregular, difícil de rachar, moderadamente resistente ao apodrecimento (LORENZI, 2008, p.142).

O roxinho (E) ocorre nos estados do Maranhão, Piauí, Bahia, Tocantins, Goiás, Mato Grosso, Mato Grosso do Sul, Minas Gerais, Espírito Santo, Rio de Janeiro e São Paulo. Sua madeira é considerada pesada, densidade $0,95 \mathrm{~g} / \mathrm{cm}^{3}$, dura, de textura fina, grã irregular, de alta resistência mecânica e muito durável (LORENZI, 2009, p.112).

Dadas as diferenças de densidade entre as madeiras, as massas dos instrumentos prontos variaram entre $65 \mathrm{~g}$ até $121 \mathrm{~g}$, ver Ex.2. O resultado estético pode ser visto no Ex.6, um conjunto multicor de flautas renascentistas que revelam a diversidade das madeiras nacionais. Do ponto de vista da comodidade de tocar o instrumento, é preferível a utilização de madeiras mais leves, porém é importante observar que as madeiras $\mathbf{A}$ e $\mathbf{B}$, apesar de leves, apresentam baixa durabilidade. Quando o instrumento é tocado, ocorre condensação de água em seu interior e, apesar da impermeabilização parcial promovida pelo óleo de linhaça, parte dessa umidade é absorvida pela madeira. Isso resulta na exposição alternada à umidade e à ausência de 
umidade, o que afeta a durabilidade da madeira, diminuindo a vida útil do instrumento. E válido notar que a flauta A possui maior massa que a flauta $\mathbf{B}, \mathbf{0}$ que provavelmente se deve a uma maior densidade daquela madeira de araucária, como sugerido por WEHR e TOMAZELLO FILHO(2000, p.163).

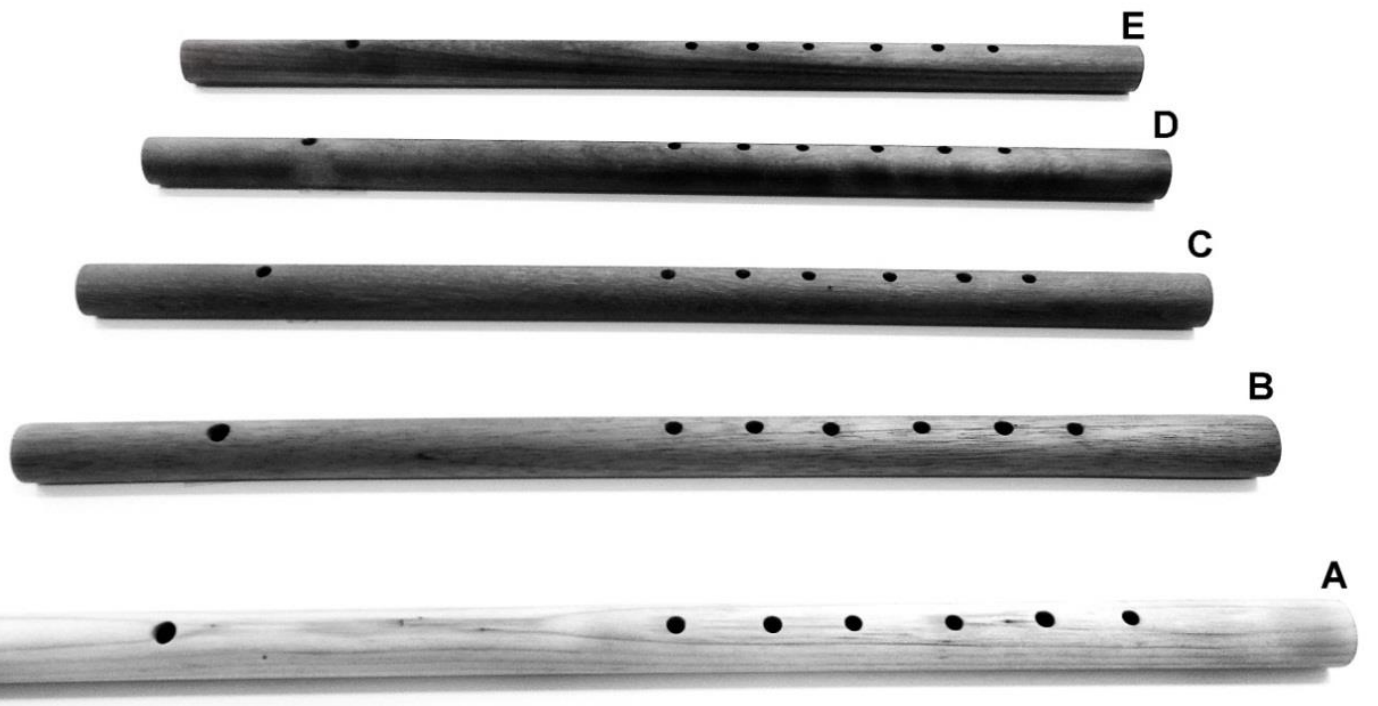

Ex.6 - Instrumentos construídos para a realização deste estudo. As madeiras utilizadas são: Aaraucária, B-cedro, C-sucupira, D-imbuia, E-roxinho.

A madeira E, apesar de ser muito resistente e durável, apresenta uma densidade alta. Por isto, é preferível que ela seja utilizada na confecção de flautas menores, tendo em conta que instrumentos maiores, como uma flauta tenor ou baixo, seriam demasiadamente pesados. Já as madeiras C e D apresentam densidades intermediárias e boa durabilidade, se caracterizando como boas escolhas, uma vez que é possível confeccionar instrumentos não muito pesados e com condições de suportar as variações de umidade.

Em se tratando da resposta das madeiras às técnicas de corte, torneamento, furação e acabamento, elas apresentaram comportamentos diversos. Por serem macias as madeiras $\mathbf{A}$ e $\mathbf{B}$ trincam, lascam e amassam facilmente durante 0 processo de torneamento, fazendo com que o processo de acabamento seja mais trabalhoso - por exemplo, a necessidade da utilização de lixas com gramaturas menores para corrigir imperfeições mais grosseiras. Por isto, tornam-se relativamente difíceis desgastes precisos, como os necessários nos furos laterais ou na embocadura ante o processo de afinação. Em contrapartida, o processo de furação transversal é rápido e fácil de ser feito.

As madeiras duras, em compensação, C, D e E, são fáceis de tornear e resultam em bom acabamento. A realização do furo transversal torna-se um processo mais demorado, porém, há maior facilidade para serem produzidos os desgastes precisos nos furos laterais e na embocadura, permitindo a confecção de instrumentos mais bem ajustados. 


\section{5 - Considerações Finais}

Neste trabalho explanatório, concluíram-se os seguintes procedimentos: a apresentação histórica da flauta transversal renascentista, suas particularidades e características; a descrição do processo de construção deste instrumento, relatando a confecção de cinco exemplares, cada um de uma madeira nacional diferente; e, por fim, a análise qualitativa dos instrumentos produzidos, considerando a influência das diferentes madeiras no processo de construção.

Foi possível demonstrar que existem madeiras brasileiras aptas para a produção das flautas renascentistas, particularmente aquelas consideradas duras e de densidade intermediária, como a imbuia e a sucupira. Verificou-se também que as mesmas técnicas de usinagem aplicadas a diferentes madeiras levam a diferentes resultados de acabamento. Sugerimos que a usinagem é a principal responsável pelas diferenças nas sonoridades destes instrumentos de sopro construídos com diferentes tipos de madeiras. Tal resultado é corroborado por LEIPP (2010, p.232-233), cujo argumento é o de que, na maioria dos casos, os tubos dos instrumentos são suficientemente espessos, a ponto de se comportarem como rígidos perante as forças que sentem devido a variações internas da pressão do ar no interior do tubo.

Pela viabilidade demonstrada no uso de madeiras nacionais não tradicionais, em trabalhos futuros, pode ser oportuno estender os testes a outras madeiras com propriedades potenciais para a confecção destas flautas. Com a finalidade de expandir e dar continuidade a esta pesquisa, poderá ser realizado um maior número de comparações através de testes acústicos.

\section{Agradecimentos}

Os autores agradecem ao Professor Dalberto Dias da Costa, por permitir a utilização da oficina mecânica e equipamentos do DEMEC-UFPR. Ao Professor Nixon Vieira Malveira, pela colaboração durante o processo de fabricação das flautas. Aos técnicos em mecânica José Antônio Miquilino Barbosa e Weslley Menezes Guimarães, pelo apoio prestado. Ao Dr. Yury Vaschenko por ceder a flauta confeccionada em imbuia para a realização dos testes.

\section{Referências:}

AGRICOLA, Martin. Musica instrumentalis deudsch. RHAU, Georg (ed). Wittemberg: 1529 e 1545.

ARBEAU, Thoinot. Orchesographie. DES PREYZ, Lehan (ed). Lengres: 1589.

ALLAIN-DUPRE, Philippe. Proportions of Renaissance Tenor Flutes and the Relationship of Verona Flutes to Foot-Length Standards. The Galpin Society Journal, v.59, p.21-28, 2006.

.Renaissance and Early Baroque Flutes: An Update on Surviving Instruments, Pitches and Consort Groupings. The Galpin Society Journal, v.57, p.53-61, 2004.

Les flutes de Rafi. Courlay: J. M. Fuzeau, 2000.

ATTAINGNANT, Pierre. Chansons Musicales. Paris: 1533.

BAINES, Anthony. Woodwind instruments and their history. New York: W. W. Norton, 1957.

BENFATTI, Maurício;GODOI, Elena; MAZUROSKI, Arsteu; FERREIRA, Rodrigo Bueno.

Cognición y cultura musical: El rol del contexto em El desarrollo Del comportamiento musical. $A$ Contratiempo, v.18, n. 3, p.1-11, 2012.

BRAGARD, Roger; DE HEN, Ferdinand. Musical Instruments in Art and History. New York: The Viking Press, 1968. 
BROWN, Howard Mayer. Flute In: The New Grove Dictionary of Music and Musicians. 6르 ed. London: Macmillan, 1980.

BYRNE, Maurice. Instruments by Claude Rafi in the Collection of Manfredo Settala. The Galpin Society Journal, v.18, p.126, 1965.

CARDAN, Jerôme. De musica. Sponius (ed). Lyon: 1546 (publicação póstuma em 1663).

CAZEAUX, Isabelle. French Music in the Fifteenth and Sixteenth Centuries. New York: Praeger Publications, 1975.

CEULEMANS, Anne-Emmanuelle. De la Vièle Médiévale au Violon du XVIle Siècle. Tournhout: Brespols, 2011.

FLEISCHER, Helmut; ZWICKER, Tilmann. Investigating dead spots of electric guitars. Acta Acustica united with Acustica, v.85, p.128-135, 1999.

v.84, p.758-765, 1998 Mechanical vibrations of electric guitars. Acta Acustica united with Acustica,

LEIPP, Émile. Acoustique et musique. Paris: Presses des Mines, 2010.

HELMHOLTZ, Hermann von. On the Sensations of Tone. New York: Dover, 1954.

LORENZI, Harri. Árvores Brasileiras: Manual de Identificação e Cultivo de Plantas Arbóreas Nativas do Brasil, v.1. 5 ${ }^{\mathrm{a}}$ ed. Nova Odessa: Instituto Plantarum de Estudos da Flora, 2008. . Árvores Brasileiras: Manual de Identificação e Cultivo de Plantas Arbóreas Nativas do Brasil, v. 2. 3aㅡ ed. Nova Odessa: Instituto Plantarum de Estudos da Flora, 2009.

MERSENNE, Marin. Harmonie Universelle. CRAMOISY, Sébastien (ed). Paris: 1636.

PEREIRA, Rodrigo Mateus; LAIBIDA JUNIOR, Albary; FREITAS, Thiago Corrêa de. Sobre o acoplamento corda-corpo em guitarras elétricas e sua relação com o timbre do instrumento. Physicæ, v.9, p.24-29, 2010.

PRAETORIUS, Michael. Syntagma musicum. HOLWEIN, Elias (ed.). Wolfenbüttel, 1619.

PUGLISI, Filadelfio. Flauti traversi rinascimentali in Italia. Firenze: S.P.E.S, 1995. . The renaissance flutes of the Biblioteca Capitolare of Verona. The Galpin Society Journal, v.32, p.24-37, 1979. . A survey of Renaissance Flutes. The Galpin Society Journal, v. 41, p.67-78, 1988.

RICHTER, Hans Georg. Holz als Rohstoff für den Musikinstrumentenbau. Celle: Moeck, 1988. ROBINSON, Trevor. The amateur wind instrument maker .Massachusetts: MIT Press, 1980. ROGNONI, Francesco. Selva de varii passaggi. Milão: 1592.

SACHS, Curt. The History of Musical Instruments. New York: W. W. Norton, 1940.

SCHWANKL, Alfred. Welches Holz ist das? Stuttgart: Franckh'sche Verlagshandlung, 1955. SMITH, Anne. The Renaissance Flute In: The Early Flute de John Slolum. Oxford: Oxford University Press, 1992.

TRICHET, Pierre.Traité des instruments de musique. Paris: 1640.

TRICOU, Georges. Claude Rafi Fleustier Lyonnais. Revue musicale de Lyon, Année I, n.2, p.25-27, 1903.

VAN EYCK, Jacob. Der Fluyten Lust-hof. MATTHYSZ, Paulus (ed). Amsterdam: 1649.

VIRDUNG, Sebastian. Musica getutsch. FURTER, Michael (ed). Bâle: 1511.

VIRGILIANO, Aurelio. II Dolcimelo. Bolonha: 1590.

WEHR, Nils Joachim; TOMAZELLO FILHO, Mário. Caracterização dos anéis de crescimento de árvores de Araucaria angustfolia (Bert.) $\mathrm{O}$. Ktze, através de microdensitometria de raios $\mathrm{X}$.

Scientia Forestalis, v.58, p.161-170, 2000.

ZACCONI, Lodovico. Prattica di musica. PÓLO, Girolamo (ed). Veneza: 1592.

\section{Notas}

${ }^{1} \mathrm{http}: / /$ www.renaissanceflute.com/ (Acessado em 23 de agosto de 2011 e 4 de abril de 2012).

${ }^{2}$ Minnesinger, no período da Alta Idade Média, era um artista poeta/músico na região da atual Alemanha.

${ }^{3} \mathrm{http}: / /$ www.accademiafilarmonica.org (Acessado em 23 de agosto de 2011 e 4 de abril de 2012).

4 Uma ideia contrária é defendida por ROBINSON (1980, p.17). 


\begin{abstract}
${ }^{5}$ Recomenda-se torneamento entre pontas, para garantir a concentricidade entre o furo longitudinal e a superfície externa da flauta (uniformidade da parede do instrumento).
${ }^{6}$ Ver o canal do autor http://www.youtube.com/user/filadelfiopuglisi (Acessado em 15 de julho de 2011 e 4 de abril de 2012).
7 Preferencialmente, sem conter nós ou imperfeições, para que o torno não inutilize a peça de madeira.

Rodrigo Bueno Ferreira é graduado em Luteria (2011) e em Letras (2009); mestre em Linguística (2013); e doutorando em Estudos Linguísticos pela Universidade Federal do Paraná. Integra os grupo de pesquisa Linguagem e Cultura UFPR/CNPq e Luteria UFPR/CNPq. Possui trabalhos relacionados à luteria, à comunicação ficcional e à Pragmática.

Henry Maas é graduado em Tecnologia em Luteria pela Universidade Federal do Paraná (2012), com habilitação em instrumentos elétricos. Possui interesse na área de design de instrumentos musicais, teorias das cores e softwares auxiliares em Luteria.

Luiz Cesar Savi é graduado em Tecnologia em Luteria (2011) e em Estatística (2000), pela Universidade Federal do Paraná e em Economia (1986), pela Universidade Federal de Santa Catarina; especialista em Finanças pelo Centro de Desenvolvimento Empresarial da Faculdade de Administração e Economia (1993). Atuou como professor no departamento de Economia da Fundação de Ensino do Valedo Itajaí, como analista de sistemas de manutenção nas Centrais Elétricas do Suldo Brasil S. A. e como superintendente de Administração Financeira na Itaipu Binacional.

Thiago Corrêa de Freitas é bacharel em Física (2007); mestre em Física (2009); e doutor em Física (2012) pela Universidade Federal do Paraná. Violinista amador, participou de cursos como as Oficinas de Música de Curitiba e integrou a Orquestra Filarmônica da UFPR. Atua como vice-coordenador e professor de Acústica no curso Superior de Tecnologia em Luteria da UFPR, sendo pesquisador do grupo de pesquisa Luteria UFPR/CNPq, na linha Acústica e Funcionamento de Instrumentos Musicais.

Aloísio Leoni Schmid é engenheiro mecânico (1990), com mestrado (1993) e doutorado (1996) em Engenharia, atuando na UFPR desde 1997. Leciona metodologia científica e disciplinas relacionadas a calor, iluminação, ar e acústica em edificações no curso de graduação em Arquitetura e Urbanismo, mestrado em Engenharia da Construção Civil. Atuou também na coordenação do curso de Luteria, sendo atualmente chefe do Departamento de Arquitetura e Urbanismo da UFPR. Na UFPR, pesquisa a simulação de edificações e tem desenvolvido aplicativos próprios, que incluem análise e auralização em acústica de salas. Tem longa prática extensionista, atuando em projetos e eventos relacionados à disseminação da música de câmera. 